\title{
SOBRE TABUS NO TEATRO INFANTOJUVENIL: QUESTÕES A PARTIR DE "O MENSAGEIRO DO REI"
}

\author{
Lucas Larcher \\ Mestre em Artes pelo Programa de Pós-Graduação em Artes da \\ Universidade Federal de Uberlândia (PPGAR-UFU). \\ Iclarcher@hotmail.com
}

Neste artigo, apresento considerações sobre os tabus no Teatro Infantojuvenil da atualidade, tendo como pano de fundo ou mote provocador os meandros e desdobramentos da criação do espetáculo "O Mensageiro do Rei", apresentado em Uberlândia - MG, no ano de 2014. Elaborado a partir de trechos de minha dissertação de mestrado, o presente texto enfoca questões relacionadas à temática, às abordagens simbólicas e à linguagem cênica que caracterizaram o processo de investigação supracitado, e tem como intuito colaborar nos estudos sobre o teatro voltado para as jovens gerações.

\section{Palavras-chave}

Teatro Infantojuvenil. Tabus. O Mensageiro do Rei.

\section{In this article, I present some considerations} about the taboos of the current Children and Youth Theatre, having as background or provocative element the meanders and unfoldings of the creative process of the a play named "The Messenger of the King", presented in Uberlândia - MG, in the year 2014. Prepared from excerpts taken from my master's thesis, the present text focuses on issues related to theme, symbolic approaches and scenic language that characterized the above mentioned research process, and aims to collaborate in studies on the theater aimed at young generations.

Keywords

Children and Youth Theatre. Taboos. The King's Messenger. 


\section{"O Mensageiro do Rei"1}

"O Mensageiro do Rei" é um texto dramatúrgico que data de 1912 e seu autor é o poeta e filósofo indiano Rabindranath Tagore ${ }^{2}$ (18611941), primeiro não-europeu a conquistar, em 1913, o prêmio Nobel de Literatura. A peça conta a história de Amal, um menino que, após perder seus pais, é adotado por seus tios, vivendo sob rígidas ordens médicas, confinado em seu quarto. Doente, observa os dias passarem através de uma janela frontal a uma casa de Correios, o lugar aonde, segundo o garoto, chegará uma mensagem enviada a ele pelo próprio rei, libertando-o para correr mundo afora.... Uma (possível) metáfora sobre o ciclo da existência humana: do campo material - o que chamamos de vida - até sua (in) finitude, ou a morte, construída através de elementos da cultura e da filosofia hindu (a vedanta ${ }^{3}$ ).

Tratando, de maneira lúdica e lírica, da (possível) temática da morte, o texto foi levado à cena por egressos e concluintes do curso de graduação em Teatro da Universidade Federal de Uberlândia. Ficando em cartaz durante os meses de maio e junho de 2014, na cidade de Uberlândia-MG, o espetáculo ${ }^{4}$ infantojuvenil

1 Este texto é uma adaptação resumida do capítulo segundo da dissertação de mestrado do autor, intitulada "Inventariando O Mensageiro do Rei - reflexões e discussões acerca do Teatro Infantojuveni" (2016).

2 Para maiores informações sobre a obra e seu autor, consultar o livro com organização de Krishna Dutta e Andrew Robinson - ainda sem tradução para o português -, indicado nas referências deste artigo.

3 Uma das mais antigas filosofias religiosas do mundo, sendo um dos alicerces de muitas das vertentes do hinduísmo. A vedanta afirma a unidade da existência, a divindade da alma humana e a harmonia de todas as religiões, que poderão conviver, assim, de maneira pacífica.

$4 \mathrm{O}$ Mensageiro do Rei configurou- se como uma montagem teatral para a conclusão do curso de Bacharelado em Teatro da Universidade Federal de Uberlândia. Além do professor responsável pela direção da peça, esta montagem contou ganhou forma através da encenação assinada por Mário Piragibe, lançando mão da linguagem e dos recursos do Teatro de Formas Animadas para abordar as questões filosóficas que se fazem presentes na trama mencionada.

Neste contexto, ao assumir o papel de ator-inventariante - responsável por unir o conjunto de bens herdados do processo criativo -, propus-me a refletir e discutir de maneira crítica algumas das questões surgidas durante o processo de criação e de apresentação do espetáculo supracitado. Como, por exemplo, os tabus relacionados à cena infantojuvenil da atualidade, assunto que emergiu ao longo de minha pesquisa de mestrado, e sobre o qual teço considerações na continuidade deste texto.

\section{Temas tabus}

Afetado por minha participação, em 2014, no III Foro Internacional de Investigadores y Críticos de Teatro para Niños y Jóvenes, ocorrido em Buenos Aires, Argentina, não consegui deixar de traçar relações entre a temática do espetáculo do qual era ator-inventariante, as discussões nas quais me envolvi e as novas referências bibliográficas que conheci neste evento. Promovido pela Asociación de Teatristas Independientes para Niños y Adolescentes (ATINA) da Argentina, em colaboração com a International Theatre for Young Audiences Research Network (ITYARN) ${ }^{5}$, o referido fórum

com o apoio da docente-estagiária Angie Mendonça, e seu elenco era composto pelos seguintes atores: Renata Sanchez, Gabriela Ananda, Jéssica Evans, Karen Marry Quintal, Rafael Michalichem, Rafael Patente, Emilliano Freitas e Lucas Larcher.

5 ATINA e ITYARN são entidades ligadas ao fazer teatral voltado para as jovens gerações, sendo a primeira uma instituição que agrega artistas argentinos, e a segunda, uma rede de pesquisadores, de diferentes partes do mundo. 
propiciou-me (re) pensar na complexidade do que vinha apresentando ao público uberlandense, ao realizar um espetáculo cuja (possível) temática da morte é destinada a crianças e jovens. Ou ainda, um espetáculo cujo tema é visto, em nossa sociedade, como um tabu.

Conforme lembra a americana Manon van de Water, uma das principais pesquisadoras de teatro voltado para crianças e jovens no quadro internacional, em seu artigo "Tabúes en teatro para niños y jóvenes: una introducción", publicado no "Boletín Iberoamericano de Teatro para la infância y la juventude no 9" (2011), pode ser considerado um tabu tudo aquilo que incomoda, traz dúvida e é polêmico, pois não é bem resolvido em uma sociedade. Nas palavras de Manon:

A palavra tabu vem da palavra Polinésia "Tapu" ou "tabu", "separado, proibido" e foi importada para a língua inglesa no final do século XVIII (dicionário etimológico Online: "Taboo"). O Oxford American Dictionary define Tabu como "Uma tradição social ou religiosa que proíbe ou restringe uma prática em particular ou uma associação proibida com uma pessoa, lugar ou coisa em particular". O que é considerado tabu, então, é específico para cada cultura ou sociedade, embora alguns tabus são mais universais, como incesto, canibalismo e homicídio intencional. Muitos tabus [...] têm a ver com sexo, violência e linguagem e que estão enraizados nas estruturas de crença moral e/ou religiosa, o que lhes converte em construções ideológicas (Water, 2011, p. 31-32, tradução nossa).

Segundo a autora, os tabus não são universais, e dependem dos diferentes contextos espaço-temporais nos quais estão inseridos. Como, por exemplo, a morte, entendida como finitude da vida, em grande parte do mundo ocidental. Mesmo tendo clareza de que em sua conjectura original - ou seja, a escritura do texto por Tagore - a morte não se configurava como um tabu, tratarei esta temática como tal, já que, diferentemente da abordagem védica, no contexto cultural em que minhas reflexões situam-se, o desligamento da existência material do corpo ainda representa um assunto cercado de restrições, em especial quando é direcionado a crianças e jovens.

Há na (s) nossa (s) cultura (s) temas tabus? Quais são? Como podemos abordá-los no Teatro Infantojuvenil? Como apresentá-los? Estas eram algumas das perguntas que se faziam a finlandesa Katariina Metsalampi e a argentina Maria Inês Falconi ao integrarem o comitê executivo da Associação Internacional de Teatro para Crianças e Jovens (ASSITEJ) ${ }^{6}$, em 2007. Com o objetivo de encontrar (novas) respostas para as interrogações mencionadas acima, as duas estudiosas propuseram uma série de oficinas dedicadas à investigação sobre temas considerados difíceis em montagens teatrais para crianças e jovens, com o intuito de desenvolver meios de trabalho entre os profissionais dos países participantes, provenientes de contextos múltiplos ${ }^{7}$.

$\mathrm{Na}$ dramaturgia infantojuvenil, os temas tabus vêm aparecendo com frequência, na atualidade, principalmente por influência dos trabalhos que vêm sendo realizados e propostos pela ASSITEJ. Seja por meio de adaptações de obras literárias não originalmente escritas para teatro ou da utilização de textos provenientes

6 A ASSITEJ configura-se como a mais importante aliança internacional de profissionais envolvidos com as práticas teatrais voltadas para as jovens gerações, tendo, hoje, aproximadamente 83 centros nacionais, diferentes redes de pesquisadores - como a ITYARN -, e membros individuais como afiliados/associados em todo o mundo.

7 Estas oficinas foram realizadas na Venezuela, em 2008, na Finlândia, em 2009, na Islândia, em 2010, em Cuba, em 2010, no Brasil, em 2010, e no Uruguai, em 2013. 
de outras culturas - como no caso de "O Mensageiro do Rei" -, e, ainda, pela dramaturgia produzida por autores que trabalham com este enfoque, questões como a (s) sexualidade (s), a (s) morte (s), a (s) violência (s), o (s) preconceito (s), entre outras, vêm ganhando um espaço significativo no conjunto de produções teatrais voltadas para as jovens gerações.

Em nosso país, percebo uma predominância da primeira possibilidade abordada quanto à dramaturgia. Utilizando-se, principalmente, de textos e/ou adaptações de histórias que servem de base para a construção de espetáculos, diferentes grupos/produções enxergam em criações não concebidas, em um primeiro momento, para a cena ou advindas de outros contextos um rico material propulsor para se abordar temas ainda postos à margem, ou obscurecidos em nossa sociedade.

No entanto, em decorrência da utilização de textos não escritos originalmente para o teatro, no Brasil, não apenas as temáticas tabus vêm aparecendo em espetáculos infantojuvenis. Algumas produções de grupos brasileiros consagrados, ao seguirem as propostas dos livros sobre os quais baseiam suas dramaturgias, propõem estruturas narrativas (cênicas ou não) não lineares, assim como exploram o cruzamento de linguagens artísticas em cena, por exemplo. Este é o caso, entre outros possíveis, do espetáculo "A cortina da babá", do grupo paulistano Sobrevento, do qual tive a oportunidade de ser espectador no ano de 2014.

Já no panorama internacional, há um grupo de autores que, ao trabalharem com esta tendência - os temas tabus -, vêm se destacando, como, por exemplo, a sueca Suzanne Osten, o alemão Lutz Hubner, Perla Szuchmacher (in memoriam) e a já citada Maria Inês Falconi. Esta última, autora de "Tengo una muñeca en el ropero" (2012), espetáculo com direção do seu marido, Carlos de Urquiza. Tratando da temática da homossexualidade para as jovens gerações, através da associação com a corriqueira expressão "sair do armário", esta peça visitou o Brasil, mais especificamente a cidade de Uberlândia-MG, em 2013.

Outro expoente nesta tendência da dramaturgia voltada para as jovens gerações e que tem como centro de interesse os temas tabus é a já consagrada canadense Suzanne Lebeau. Fundadora da Companhia Le Carrousel, ao lado de seu marido e diretor teatral Gervais Gaudreault, Lebeau vem se tornando uma das principais figuras no que se refere ao pensamento sobre questões intrínsecas ao fazer teatral infantojuvenil. Em seu artigo "De la censura y de la autocensura...", publicado no "Boletín Iberoamericano de Teatro para la infância y la juventude $n^{\circ} 7$ " (2006), Lebeau compartilha com o leitor sua experiência ao longo de aproximadamente quarenta anos de carreira. Para a autora:

[...] a compreensão das crianças é sutil, global, profunda, e vai muito além e muito mais fundo do que tudo o que se pode imaginar, prever, supor, definir, e nunca são as crianças que impõem limites para o que você pode mostrá-las. As crianças são abertas e estão disponíveis. Os preconceitos sobre o que pode e deve ser o teatro aumentam com a idade. Os adultos, no entanto, têm uma ideia muito precisa do que pode ou não pode ser apresentado às crianças. E o perigo é que esta convicção íntima que cada adulto tem sobre o que é bom para as crianças é totalmente subjetiva. Está baseada nas memórias de infância, numa nostalgia por aquilo que foi desejado viver e o que se viveu, e, acima de tudo, colorido pela tradicional relação adultocriança de subordinação didática em que $\mathrm{o}$ adulto é aquele que sabe e a criança aquele que aprende (Lebeau, 2006, p. 101, tradução nossa). 
Chamando a atenção para o fato de serem os adultos os responsáveis pela censura no teatro para as jovens gerações, uma vez que se autocensuram ao terem dificuldades para tratar de determinados assuntos, Lebeau colabora para que nós, artistas-criadores, possamos nos interrogar acerca de nossas criações. .... Temos o direito de inventar um mundo mais seguro, escondendo a verdadeira realidade um mundo, por vezes, imperfeito e assustador - das jovens gerações? ... cabe ao artista apresentar uma visão pré-estabelecida, ou conclusiva, sobre questões tão complexas, como os temas tabus, a crianças e jovens, reproduzindo a noção autoritária do apartheid das jovens gerações? ... Estes são alguns dos questionamentos que formam o oceano de interrogações - pistas e possibilidades de caminhos trazidas após a leitura do texto de Lebeau.

Apoiado nas contribuições trazidas pelos escritos de Manuel Sarmento - docente do Programa de Estudos da Criança da Universidade do Minho, em Portugal -, arrisco-me a responder às questões expressas por Lebeau à luz de um olhar sociológico para a infância. Sendo a (s) infância (s) e a (s) juventude (s) construções sócio-históricas, é possível dizer que a tentativa de delimitar e afastar seus universos da esfera do que é considerado "para" ou "próprio dos adultos" vem sendo inviabilizada ou apresentando sinais de fracasso e esgotamento desde o advento do que chamamos de Segunda Modernidade.

Conforme lembra Sarmento e a também professora Rita Marchi, no artigo "Radicalização da infância na Segunda Modernidade: Para uma Sociologia da Infância crítica" (2012), enquanto "o modelo de criança da primeira modernidade nasce ligado a uma sociedade patriarcal, monogâmica, onde o modelo de adulto está preso a papéis sociais e sexuais bem definidos" (Sarmento; Marchi, 2012, s.p), na Segunda Modernidade "as crianças passam a arcar com a construção de sua própria biografia e de serem responsabilizadas pelo sucesso ou fracasso desta tarefa." (Sarmento; Marchi, 2012, s.p).

Neste contexto, é possível afirmar, como argumentam os autores, que "a Segunda Modernidade, ao fazer de cada criança um 'indivíduo de direitos' responsável por sua auto-realização, liberta-a relativamente dos laços que a atavam solidamente às instituições família e escola" (Sarmento; Marchi, 2012, s.p), e, assim, da hegemônica proteção (ou poder) conferida, até então, ao (s) adulto (s) responsável (is). Fato este que possibilita, na maioria dos casos, às jovens gerações a construção de um conhecimento sobre o mundo no qual a alienação e/ou desinformação não se faz mais possível, não sendo apenas reguladas pela ação de adultos sobre crianças e jovens.

Parcialmente emancipadas dos papéis sociais institucionalizados na Primeira Modernidade - o de filhos (as) e o de "aluno (as) ", apenas -, as jovens gerações encontram também nos meios de comunicação importantes aliados na superação do "duplo ofício" - utilizando a expressão de Sarmento e Marchi - a que muito tempo foram submetidas. Atingindo crianças e jovens, diferentes mídias colaboram para que a interatividade - um dos traços identificadores da (s) cultura (s) da (s) infância (s) - possibilite a eles (se) apropriarem, (re) inventarem e (re) produzirem o mundo que os rodeia e, consequentemente, não permite a exclusão das jovens gerações do "mundo dos adultos", com sua dinâmica própria, que inclui conteúdos, mecanismos expressivos... direitos e deveres. 
Desta maneira, os modos como expressamos as temáticas tabus são o que caracterizam um olhar honesto perante crianças e jovens. Não encerrando, por exemplo, um final moralizante, nós, artistas-criadores, permitimos leituras polissêmicas de uma obra, assim como possibilitamos o descortinamento de diferentes camadas de leituras sobre um assunto. Principalmente, através do uso do simbólico, explorado muitas vezes por meio de metáforas, podemos, talvez, aproximar-nos efetivamente do público para o qual, em maior ou menor instância, dirigimos nossas criações, como fizeram e fazem nomes de referência na produção artística para crianças e jovens.

Em uma sociedade em que a televisão, a internet, o cinema, entre outros meios de comunicação, bombardeiam crianças, jovens, adultos e idosos com um discurso, por vezes, vulgarizado, o teatro - parafraseando as palavras de Lebeau - deve ser um disparador, ou detonador, creio eu. Trazendo perguntas, muito mais do que respostas, o teatro possibilita que o público veja, na sua frente, seus fantasmas e, então, possa enfrentá-los. Mesmo que estes fantasmas não sejam levados à cena em uma linguagem realista. Acredito que o teatro, por meio do poético, abra caminhos para olhares diversos, outros, nos quais novas perspectivas sobre um assunto possam ser enxergadas, e não mascaradas. E julgo ser este o caso de "O Mensageiro do Rei", conforme abordarei nos próximos tópicos.

\section{Abordagens simbólicas}

Tratando de um (possível) tema próprio da condição humana ou existencial - a morte -, e desenvolvido dentro de um contexto no qual a magia feérica faz-se presente, "O Mensageiro do Rei" - enquanto texto - permite ser associado às narrativas maravilhosas. Ou, melhor, remete aos Contos de Fadas: histórias cuja efabulação básica "expressa os obstáculos ou provas que precisam ser vencidos, como um verdadeiro ritual iniciático, que o herói alcance sua auto-realização existencial”, conforme apresenta Nelly Novaes Coelho no livro "O Conto de Fadas" (1987, p. 13).

Contudo, no caso de "O Mensageiro do Rei", a aproximação entre o texto dramatúrgico e os Contos de Fadas ${ }^{8}$ - conforme a concebo, a partir de um olhar ocidental - não está ancorada na estrutura de enredo, mas, sim, na abordagem poética e/ou lírica do mundo realizada por Tagore. Assim, por meio da fusão de elementos reais - como o cotidiano do menino Amal e de seu entorno - e fantasiosos - como a aparição mágica do arauto e do médico reais no terceiro ato do texto -, o autor indiano consegue abordar a (possível) temática da morte que, neste trabalho, é analisada sob o prisma ocidental - ou como um tabu -, de maneira que o sentido da carta que o menino Amal tanto aguarda possa ser ampliado e, assim, possibilite ao leitor associá-lo, entre outros, à chegada da morte e/ou à obtenção da liberdade.

Esta abordagem poética e/ou lírica a que me referi no parágrafo anterior é alcançada por meio da exploração de diversos símbolos ao longo do texto. Definido como signos que têm o poder de representar um significado por meio de um significante diferenciado, os sím-

\footnotetext{
8 Sobre este aspecto, é importante destacar que uma das primeiras teses defendidas no Brasil relacionadas ao teatro voltado para as jovens gerações versa sobre a aproximação entre os Contos de Fadas e a dramaturgia infantojuvenil de nosso país. Este trabalho intitula-se "Contos de Fadas na Dramaturgia" (1995), de llíada Silva Alves de Castro, realizado na Escola de Comunicações e Artes (ECA) da Universidade de São Paulo (USP).
} 
bolos podem ser pensados como um conjunto de esquemas representativos concretos (bidimensionais, tridimensionais ou sonoros) que expressam significados abstratos e não estritos por meio de convenções, semelhanças e contiguidade. Ou seja, possibilitam a exploração de significados, mediando e/ou integrando conteúdos inconscientes à consciência.

Investigando o imaginário humano, Gilbert Durand apresenta em seu livro "A imaginação simbólica" (2000) alguns importantes apontamentos sobre as formas de representação - e as teorias vinculadas a elas - encontradas pelo homem como maneiras expressivas e de comunicação ao longo da história. Contrastando com a definição de alegoria, o autor diz que o símbolo seria o inverso desta, já que "a alegoria parte da ideia abstrata para chegar a uma figura, enquanto o símbolo é primeiro e em si figura e, como tal, fonte, entre outras coisas, de ideias" (Durand, 2000, p. 10).

Assim, Durand colabora para o entendimento dos símbolos como formas de representação cuja dimensão concreta - ou significante - não é restritiva, pois, tratando-se de/evocando imagem, possibilita que suas significações inesgotáveis sejam expressão de desejos e/ ou inquietudes humanas. Ou, ainda, remeta a indizíveis e invisíveis significados conforme o contexto em que está inserido - podendo ser universal -, e/ou às referências de quem o interpreta, sendo individual.

Desvelando tensões contraditórias, os símbolos possuem um caráter dialético, uma vez que, transcendendo os sentidos individuais, tornam-se portadores de significados coletivos, expressos por múltiplos e díspares modos. Para o autor, é este fato que caracteriza a imaginação simbólica, seu foco de análise. Por isso, ele, assim, completa suas considerações sobre os símbolos:

Este duplo imperialismo - simultaneamente do significante e do significado - na imaginação simbólica marca especificamente o signo simbólico e constitui a flexibilidade do simbolismo. O imperialismo do significante, que ao repetir-se chega a integrar numa única figura as qualidades mais contraditórias, tal como o imperialismo do significado, que chega a transbordar por todo o universo sensível para se manifestar, repetindo incansavelmente 0 acto epifânico, possuem o caráter comum da redundância (Durand, 2000, p.13).

Esta redundância da qual fala Durand faz com que os símbolos venham sendo explorados, há muito, em diversas áreas do conhecimento. Dada sua natureza simultaneamente consciente e inconsciente, racional e irracional, os símbolos são, por um lado, acessíveis à consciência ou à razão, e, por outro, permanecem ocultos a ambas. Fato este que proporciona a aproximação entre o inconsciente e o consciente, tão explorada pela psicanálise, que se debruça sobre a interpretação do simbolismo através de suportes como, por exemplo, os Contos de Fadas.

A capacidade de simbolização surge no ser humano por volta dos dois anos de idade, momento no qual a criança começa a assimilar a evocação de elementos ausentes. O simbólico manifesta-se, então, como uma maneira de compreensão das relações entre representação e pensamento. Como bem explicou o epistemólogo e psicólogo suíço Jean Piaget, os símbolos tomam parte decisiva na formação do homem à medida que o permitem organizar sua experiência, como também, compreendê-la.

Ingrid Dormien Koudela, em seu livro "Jogos Teatrais" (2013), no qual a autora aborda muitas 
das questões relacionadas a este trabalho, relembra os estudos de Piaget ao pontuar alguns aspectos sobre a função simbólica na criança. Dedicando-se à relação entre a brincadeira infantil e o fazer teatral- enquanto manifestação expressiva humana diante de uma plateia -, a autora retoma a gênese da representação por meio de símbolos na infância. Para ela:

\begin{abstract}
A "função simbólica" é constituída a partir do momento em que a criança representa um ato, uma ação, na ausência de seu contexto habitual. Essa representação em ato tem o significado de um primeiro distanciamento da "vida corrente" (experiência imediata) (Koudela, 2013, p. 34).
\end{abstract}

Tendo como base os expostos de Koudela, digo que a partir do momento que a criança passa a conceber a representação, por meio da aquisição da função simbólica, "surge o comportamento que envolve essencialmente a expressão por meio de imagens" (Koudela, 2013, p. 34), sejam elas expressas com a ajuda de seu corpo, projetando-se em seus brinquedos ou através de desenhos, primeiramente. $\mathrm{E}$, posteriormente, pela representação gráfica escrita - com a alfabetização -, assim como por outras formas expressivas, como a (s) arte (s) - aqui entendida (s) como atividade (s) humana (s) ligada (s) às manifestações estéticas e comunicativas concebidas conscientemente para estes fins.

$\mathrm{Na}$ (s) arte (s), de um modo geral, os símbolos sempre exerceram fundamental papel ao se configurarem como meio pelo qual se expressam artistas-criadores das mais diferentes manifestações. Nela (s), os mais diferentes suportes proporcionam que o símbolo se expresse, conferindo-Ihe o caráter multívoco. Deste modo, por exemplo, em um texto, palavras evocam imagens maleáveis ao capricho do contexto em que estão inseridas, assim como o do leitor - como no caso de "O Mensageiro do Rei", com os termos carta, janela, casa, outono... -; e, num espetáculo teatral, a cenografia, a iluminação, os figurinos, os corpos dos atores, entre outros, possibilitam leituras sensíveis sobre a obra.

Como os significantes e significados detêm relações profundas com o (s) produtor (es) da (s) representação (ões), desvelando o (s) caminho (s) de seu (s) pensamento (s), parece-me interessante destacar que no Teatro Infantojuvenil este aspecto revela o modo como artistas-criadores - adultos - supõem que seu público - prioritariamente, crianças e jovens - enxergam, compreendem e representam o mundo. Isto por meio da exploração do simbólico utilizado nas criações em questão, podendo ser esta direcionada a "lugares comuns" interpretativos ou a inexauríveis e potentes dimensões de seu (s) imaginário (s).

$E$ é justamente este último direcionamento da simbolização que permite leituras múltiplas e não a lição de moral. Trata-se, portanto, da capacidade elucidativa do símbolo, que não se propõe a impor uma determinada interpretação, mas a emitir uma hipótese sobre o sistema escolhido através das apreensões do (s) espectador (es) - no caso do teatro. E, então, rompendo com a rotina de aceitação passiva de saberes "prontos e acabados", ou teses aquilo que deve ser aprendido no/com o teatro.

\section{A linguagem cênica}

No campo da encenação, parece-me que, pouco a pouco, a estética convencional que neutraliza conflitos, cujos conteúdos tornamse limitados e censurados ao serem tratados 
de forma didática e/ou unilateral, suavizando-os, está perdendo seu espaço nas produções voltadas para o público infantojuvenil. Em contraposição, variadas proposições, de diferentes filiações estéticas, borram os limites de linguagens artísticas, permitindo, a título de exemplo, que tabus possam ser experienciados pelo público em suas fruições teatrais, como lembra Water:

Os tabus podem se infiltrar no Teatro Infantojuvenil de várias maneiras: no conteúdo, na forma e no estilo. Os tabus podem ser fáceis e ambíguos; sexo, sexualidade, violência e linguagem ofensiva estão entre os tabus mais comuns, e refletidos frequentemente em conteúdos "seguros". Mas os tabus podem ser ocultos e ideológicos. Teatro do absurdo para crianças e jovens, finais abertos, tramas não lineares, imagens associativas e falta de protagonistas ou personagens claros capazes de serem identificados são muitas das vezes suspeitos. Nestes casos não está claramente diferenciada a fina linha entre "tabu" e "polêmico" ou "desafiante" (Water, 2011, p. 36 , tradução nossa).

Partindo do princípio de que os tabus não são expressos no teatro apenas pela temática tratada em uma dramaturgia, mas também pelo modo de se abordar estes temas e/ou configurar a estrutura de uma montagem como apontado há pouco -, atento para o fato de que, em "O Mensageiro do Rei", ao utilizarmos de uma imagem poética ou simbólica para representar a transformação do menino Amal em mensageiro real, nós, artistas-criadores, exploramos a possibilidade de um final aberto à trama apresentada. Neste, dada as alternativas indicadas pelo texto de Tagore, o espectador podia compreender a mudança de categoria do menino como: a morte, enquanto finitude da existência... a liberdade de um ser não mais preso à sua porção material, ou corpo... entre outras interpretações.

Quebrando a concepção de que o teatro para crianças e jovens deve ter um final com sentido restrito (e feliz), trabalhamos na tentativa de não nos autocensurarmos e, assim, não censurar aquilo que era mostrado ao público que assistiu ao espetáculo - retomando a fala de Lebeau. Deste modo, a encenação revelava como o adulto-criador enxerga as crianças e jovens para os quais (também) se dirigia, que, - como já dito-, estão, hoje, indiscutivelmente, em interação com o "mundo dos adultos" e expostos aos meios de comunicação em seu (s) cotidiano (s). E que viam em cena uma nova perspectiva sobre a qual a morte pode ser encarada, através de uma abordagem a partir da ótica de outra cultura (a indiana).

Acredito que não há temáticas, conteúdos ou estéticas específicas para lidar com crianças e jovens, mas, sim, um vasto conjunto de possibilidades e configurações que tão bem caracterizam a cena infantojuvenil atual. Assim, destaco, também, que "O Mensageiro do Rei" foi construído com base na premissa de que independente do público, o rigor criativo - seja na encenação, nas interpretações e nos elementos visuais e sonoros - é fundamental em uma produção teatral.

Em "O Mensageiro do Rei", concebendo o espetáculo como antes de tudo obra artística - independente do público para o qual se destinava -, a meu ver, a sua encenação aproximava-se do conceito de linguagem cênica expresso por Fátima Ortiz em seu artigo "A linguagem cênica no teatro para crianças", contido no livro "O teatro dito infantil" (2003). Tendo em vista que este se refere "à somatória de elementos que permitem aos artistas se expressarem no palco" (Ortiz, 2003, p. 59), e 
que a linguagem da qual fala a autora "se faz através do equilíbrio dos elementos lúdicos, mágicos e reais" (Ortiz, 2003, p. 60), ressalto a importância do (s) elemento (s) simbólico (s) - tanto na dramaturgia, quanto na encenação - no espetáculo em questão, assim como a exploração da dimensão lúdica nele observada.

Penso que o fazer teatral sempre irá causar uma fusão entre o contexto da ficção ou mágico/imaginário e o contexto real, já que se pauta na interpenetração destas duas instâncias a partir, justamente, da dimensão lúdica de uma criação. A ludicidade destaca-se como o meio pelo qual nós, artistas-criadores, podemos navegar por estes dois universos, explorando suas contradições e possibilidades articulatórias.

Além disso, a ludicidade, com suas raízes e derivações, como tão bem elucida Johan Huizinga na consagrada obra "Homo Ludens" (1993), cobre todo o terreno do jogo. Sendo, também, um elemento constitutivo da (s) cultura (s) da (s) infância (s) - de acordo com Sarmento -, é inerente à existência do homem, independente das fronteiras etárias, e, consequentemente, às brincadeiras das crianças, sejam elas - nas categorias sistematizadas por Piaget - de caráter sensório-motor, simbólico ou de regras, que se aproximam da atividade teatral.

Sendo assim, digo que a partir da década de setenta do século passado, ao se aproximar o Teatro Infantojuvenil da noção de jogo, algumas características próprias do ato de brincar - ou o jogo dramático infantil - evidenciam-se na morfologia dos espetáculos voltados para as jovens gerações. Pois, se é por meio do jogo, ou brincadeira, que a criança e o jovem elaboram dramatizações e/ou metáforas sobre as relações estabelecidas e apreendidas do mundo que os cerca, será através do teatro que os mesmos poderão observar - e, talvez, intervir - as/nas possibilidades de representação da existência humana.

Koudela, mais uma vez, em seu livro já citado, colabora para esta pesquisa ao descrever as modificações nas montagens voltadas para as jovens gerações em função da observação do jogo, desde a década mencionada. Partindo de sua prática como artista e educadora, Koudela revela algumas das consequências do quadro de alterações, no qual a veiculação de teses, o ilusionismo e o relacionamento vertical entre artistas-criadores e as jovens gerações reorganizam-se. Nas palavras da autora:

Ao romper a relação autoritária e abandonar a pretensão de veicular uma tese, o artista adulto encontra no próprio universo infantil a matéria para a formulação do espetáculo. Essa transformação radical gerou necessariamente uma nova concepção de processo. Os conceitos tradicionais de direção, atuação, cenografia, como atividades compartimentadas deixaram de ter sentido, sendo substituídos pelo processo de descoberta realizado em grupo, onde o jogo de improvisação incorpora esses elementos numa criação orgânica. Enquanto o ator passa a participar da autoria do espetáculo, o papel do diretor pode ser qualificado como coordenador geral. A direção tradicional é substituída por propostas que favorecem o surgimento da relação de jogo, base sobre a qual se constrói a montagem. Em muitos casos, o texto serve apenas como pretexto ou ponto de partida e o material da encenação é extraído do processo de pesquisa e da criação coletiva (Koudela, 2013, p. 104).

Ao propor um universo distinto do da fábula, a encenação de "O Mensageiro do Rei" utilizava-se do espaço cênico como "área de jogo", aberta a leituras polissêmicas dos espectadores, e que é capaz de se adaptar às diversas 
necessidades e ambientações propostas pela história a ser contada. Tal como uma janela (Figura 1) - a única ventana pela qual o menino Amal, em seu quarto escuro, pode ver o mundo -, a linguagem cênica de um espetáculo infantojuvenil, a meu ver, deve ser um convite para um olhar que se estende para além do horizonte. Ou, ainda, a permissão para se imaginar, e conhecer o que, até então, é chamado de desconhecido: os tabus.

Figura 1: Desenho extraído do diário de bordo do ator-inventariante.

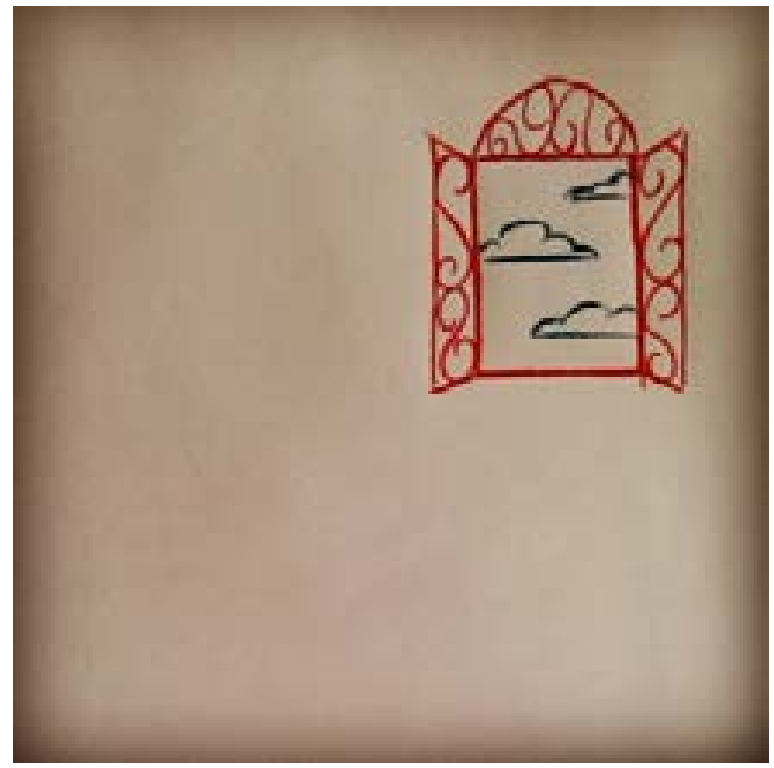

Fonte: Lucas Larcher, 2013.

Referências

CASTRO, Ilíada Alves de. Contos de Fadas na Dramaturgia. 1995. [s.p.]. Tese (Doutorado) Escola de Comunicação e Artes, Universidade São Paulo (USP), São Paulo, 1995.

COELHO, Nelly Novaes. O conto de fadas. São Paulo: Ática, 1987.
DURAND, Gilbert. A Imaginação Simbólica. Lisboa: Edições 70, 2000.

DUTTA, Krishna; ROBINSON, Andrew. Rabindranath Tagore: An Anthology. Nova York: St. Martin's Press, 1998.

HUIZINGA, Johan. Homo Ludens - O jogo como elemento da cultura. 4.ed. São Paulo: Perspectiva, 1993.

KOUDELA, Ingrid Dormien. Jogos Teatrais. 7. ed. São Paulo: Perspectiva, 2013.

LARCHER, Lucas. Inventariando O Mensageiro do Rei - reflexões e discussões acerca do Teatro Infantojuvenil. Dissertação (Mestrado em Artes) - Instituto de Artes, Universidade Federal de Uberlândia (UFU), Uberlândia, 2016.

LEBEAU, Suzanne. De la censura y de la autocensura.... Boletín Iberoamericano de Teatro para la infância y la juventude, ASSITEJ, Espanha, 2006, n. 7, p. 97-111. (Tradução nossa)

ORTIZ, Fátima. O espetáculo: A linguagem cênica no teatro para crianças. In: KUHNER, Maria Helena (Org.). O Teatro dito Infantil. Florianópolis: Fundação Cultural de Blumenau, 2003.

SARMENTO, Manuel Jacinto; MARCHI, Rita de Cássia. Radicalização da infância na Segunda Modernidade: Para uma Sociologia da Infância crítica. Configurações - Revista de Sociologia [Online], 2008, n. 4, [s.p.].

TAGORE, Rabindranath. O Mensageiro do Rei. [S.I.]: [s.n.], 1912. (Tradução de Mário Piragibe). 
WATER, Manon van de. Tabúes en teatro para niños y jóvenes: una introducción. Boletín lberoamericano de Teatro para la infância y la juventude, ASSITEJ, Espanha, 2011, n. 9, p. 3144. (Tradução nossa).

Recebido: 25/03/2017 Aprovado: 14/06/2017 